\title{
Corneal lamellar grafting to repair late complications of mitomycin $\mathrm{C}$ trabeculectomy
}

This article was published in the following Dove Press journal:

Clinical Ophthalmology

27 March 2010

Number of times this article has been viewed

Takeo Fukuchi

Hidenobu Matsuda

Jun Ueda

Akiko Yamada

Kieko Suda

Haruki Abe

Division of Ophthalmology and Visual Science, Graduated School of Medical and Dental Sciences, Niigata University, Niigata, Japan
Correspondence:Takeo Fukuchi Division of Ophthalmology and Visual Science, Graduated School of Medical and Dental Sciences, Niigata University, I-757 Asahimachi, Niigata 95 I-85 I0, Japan

Tel +8I 252272296

Fax +8I 252270785

Email tfuku@med.niigata-u.ac.jp
Purpose: To report corneal lamellar grafting to repair the late-onset complications after MMC trabeculectomy.

Methods: Multiple case reports.

Results: A 76-year-old male with primary open-angle glaucoma (POAG) and a 55-year-old male with late developmental glaucoma complicated by bleb leaks from a microhole 10 and eight years after surgery, respectively. Severe ciliochoroidal detachment and a shallow anterior chamber were persistent in one case and bleb-related infection recurred in another. Additionally, a 46-year-old male with POAG had hypotony maculopathy with a giant ischemic bleb 18 months after surgery. Although these patients were quite resistant to medical and surgical treatments, they were successfully treated by corneal lamellar grafting without complications. Conclusions: Tectonic corneal lamellar grafting is a reliable and final surgical method to improve severe cases of hypotony maculopathy or bleb leak after mitomycin $\mathrm{C}$ trabeculectomy.

Keywords: mitomycin C, trabeculectomy, postoperative complications, hypotony maculopathy, bleb leak, corneal lamellar grafting

\section{Introduction}

Mitomycin C (MMC) trabeculectomy is still used worldwide as a convenient and effective method to reduce intraocular pressure (IOP) in glaucomatous eyes that cannot be controlled with maximum tolerated doses of medications. ${ }^{1-7}$ Soon after Chen ${ }^{1}$ introduced $\mathrm{MMC}$ as an adjunctive agent during trabeculectomy, cases of hypotony associated with a shallow-to-flat anterior chamber or ciliochoroidal detachment were often seen because of the strong antifibroblastic effect of MMC. ${ }^{8-10}$ Once such complications occurred, they tended to persist for long periods. MMC trabeculectomy with laser suture lysis ${ }^{11-13}$ or non-penetrating filtering surgery ${ }^{14,15}$ were recommended to decrease postoperative complications related to hypotony in the early phase. Although these reliable modifications greatly reduced the occurrence of hypotony maculopathy, this complication still occurs. In addition, late-onset hypotony after MMC trabeculectomy often occurs with a bleb leak because of microhole formation. ${ }^{16-20}$ While a bleb leak as a result of microhole formation may result in hypotony, a shallow anterior chamber, or ciliochoroidal detachment, it is thought to be related closely to blebitis or endophthalmitis as the most severe complications after MMC trabeculectomy. ${ }^{21,22}$

We treated three patients who had severe complications associated with MMC trabeculectomy with corneal lamellar grafting. Two patients had bleb leaks from a microhole and another had a rare case of slow-onset hypotony maculopathy. We present these cases and discuss corneal lamellar grafting as a reliable and final surgical 
treatment for severe hypotony or bleb leaks after MMC trabeculectomy.

\section{Case reports Case I}

A 76-year-old Japanese male with POAG underwent MMC trabeculectomy in his left eye in July 1994 (at 65 years of age). The surgical method for MMC trabeculectomy was followed as previously reported. ${ }^{23} \mathrm{MMC}$ was applied at $0.02 \mathrm{mg} / \mathrm{mL}$ for five minutes. His postoperative left IOPs were kept between 9 and $12 \mathrm{mmHg}$. In December 2004, he visited our clinic complaining of left conjunctival infection and blurred vision. His left eye had associated leakage from a microhole of the bleb with Seidel's phenomenon (Figure 1A), a shallow anterior chamber of Grade 1 by Spaeth's classification ${ }^{24}$ (Figure 1B), and a marked circumferential ciliochoroidal detachment.

We tried several medical and surgical treatments, including administration of an oral carbonic anhydrase inhibitor, injection of autologous blood into the bleb, and repeated bleb reformation with compression sutures, but they provided only temporal relief. Finally, we decided to perform corneal lamellar grafting.

After the anterior chamber formation with hyalonate and conjunctival incision, surgical debridement was performed on scarred conjunctiva and soft tissues on the sclera. Halflayered corneoscleral tissues, including the area of weakened spongy sclera, were dissected away using a corneal trephine $5.5 \mathrm{~mm}$ in diameter (Figure 2A). Clean, healthy edges of the dissection were regularized (Figure 2B). Then, donor corneal tissue was used to repair the corneoscleral defect. A round lamellar preserved corneal piece, $5.5 \mathrm{~mm}$ in diameter and $0.8 \mathrm{~mm}$ thick, was made using a corneal trephine. The piece was sutured exactly to the patient's cleaned-up corneoscleral area with 10-0 nylon (Figures 2C and 2D). A total of eight sutures were placed and made water tight. The conjunctiva was left free except for both edges, which were grafted and sutured with 10-0 nylon. An antibiotic, ofloxacin, and a steroid, $0.1 \%$ betamethasone, were prescribed as postoperative medications to be taken four times a day. Oral prednisolone

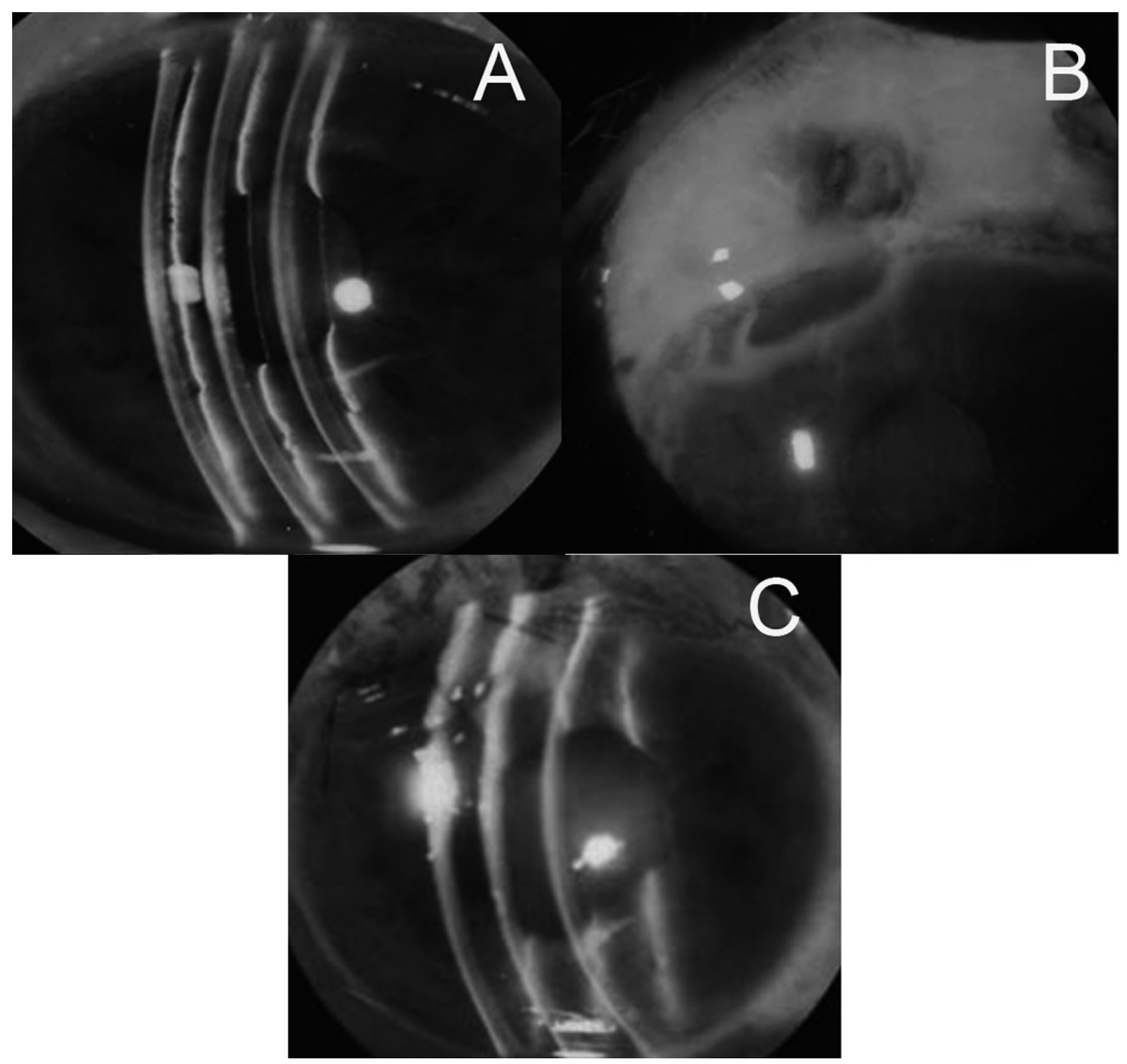

Figure I Case I was complicated by a shallow anterior chamber (A) because of bleb leakage with Seidel's phenomenon (B). After corneal lamellar grafting, the anterior chamber had kept deep (C) and the IOP had also increased.

Abbreviation: IOP, intraocular pressure. 


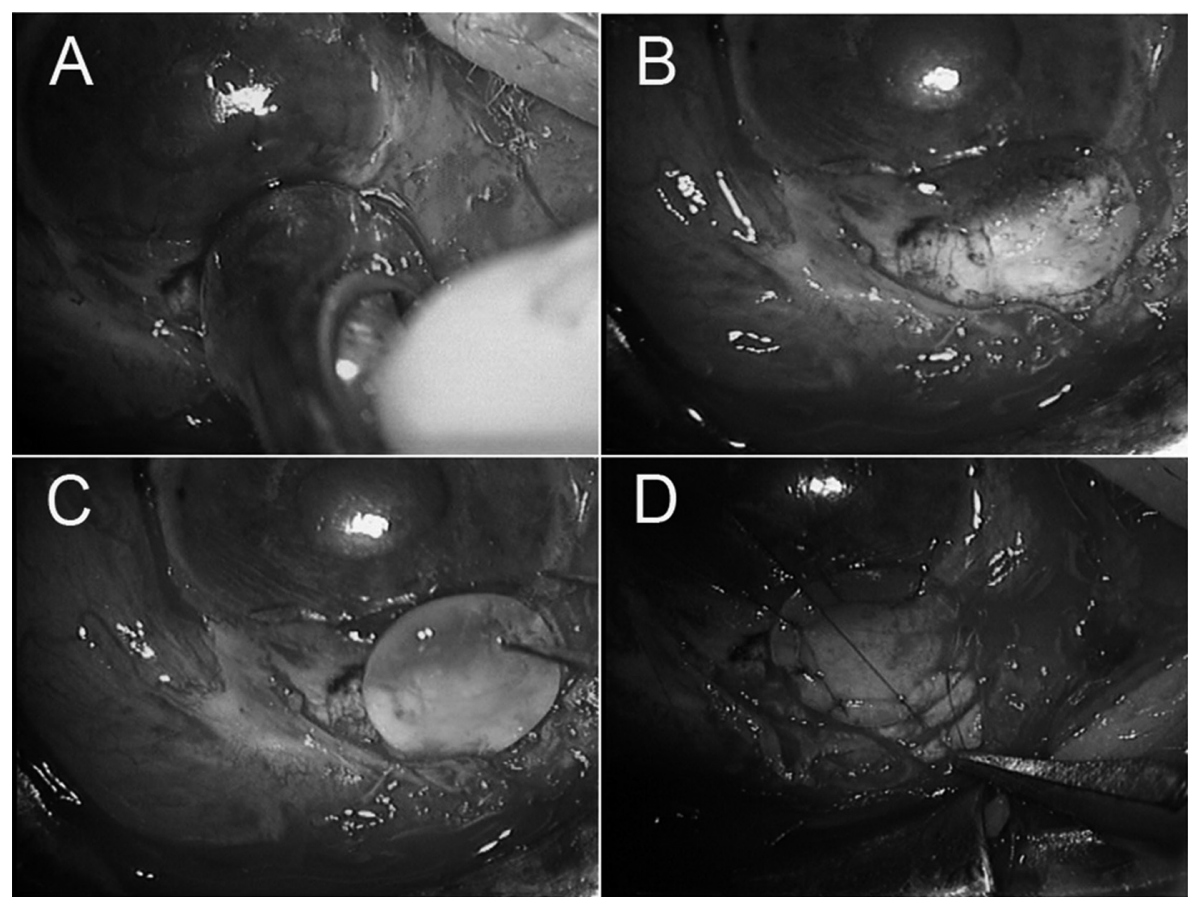

Figure 2 Using a corneal trephine (5.5 mm diameter), half-layered corneoscleral tissues was dissected away (A). Clean, healthy edges of the dissection were regularized (B). Then a donor's lamellar, round, preserved corneal piece with $5.5 \mathrm{~mm}$ diameter and $0.8 \mathrm{~mm}$ thickness was placed (C) and was sutured exactly to the patient's corneoscleral area with I0-0 nylon (D).

was prescribed at $30 \mathrm{mg}$ per day and then tapered off at the end of the three-week postoperative period.

His left IOP increased to $48 \mathrm{mmHg}$ on the second day. The IOPs were controlled between 15 and $18 \mathrm{mmHg}$ with topical medications. The left anterior chamber remained deep without subsequent ciliochoroidal detachment.

\section{Case 2}

A 55-year-old Japanese male diagnosed with late developmental glaucoma received MMC trabeculectomy by a procedure similar to that used in case 1 in 1992 (at 42 years of age). His left IOP was kept between 5 and $8 \mathrm{mmHg}$ without medication. When blebitis with bleb leak from a microhole occurred in his left eye in December 2000, medical treatments were effective. After blebitis recurred in March 2001, the bleb resection and autologous free conjunctival patch grafting were performed after administration of an oral carbonic anhydrase inhibitor and injection of autologous blood into the bleb. In 2004, bleb leak from a microhole recurred and the IOP decreased to $5 \mathrm{mmHg}$. We performed corneal lamellar grafting using the same procedure as in case 1. After increasing to $27 \mathrm{mmHg}$ on the next day, the IOPs were maintained between 10 to $13 \mathrm{mmHg}$ with topical medications, and no leakage or blebitis occurred again after the surgery.

\section{Case 3}

A 46-year-old Japanese male with POAG underwent MMC trabeculectomy in both eyes in April 1996 (at 42 years of age). The postoperative IOP decreased to $11 \mathrm{mmHg}$ at three months, $7 \mathrm{mmHg}$ at six months and $4 \mathrm{mmHg}$ at 12 months. Finally, his left IOP was $3 \mathrm{mmHg}$ with a giant ischemic bleb (Figure 3A) and typical hypotony maculopathy (Figure 3B) at 18 months post surgery. The corrected visual acuity was 20/20 at three months and 4/20 at 18 months. Although we tried several medical and surgical treatments, including oral carbonic anhydrase inhibitors, conservative injection of autologous blood, surgical compression sutures, and direct conjunctival cover, his hypotony maculopathy never improved. Finally, we performed corneal lamellar grafting following the same procedure as described for case 1 (Figures 3C and 3D) at 40 months after the initial MMC trabeculectomy. Similarly the IOP increased up to $46 \mathrm{mmHg}$ on the next day, but decreased to $22 \mathrm{mmHg}$ within a week with oral and topical medications. The hypotony maculopathy improved within two weeks. The corrected visual acuity increased to $10 / 20$ at 12 months and 18/20 at 60 months after the corneal grafting. His left IOP has remained between 14 and $18 \mathrm{mmHg}$ only with topical medications, and his left visual field defect has shown no notable progression. 


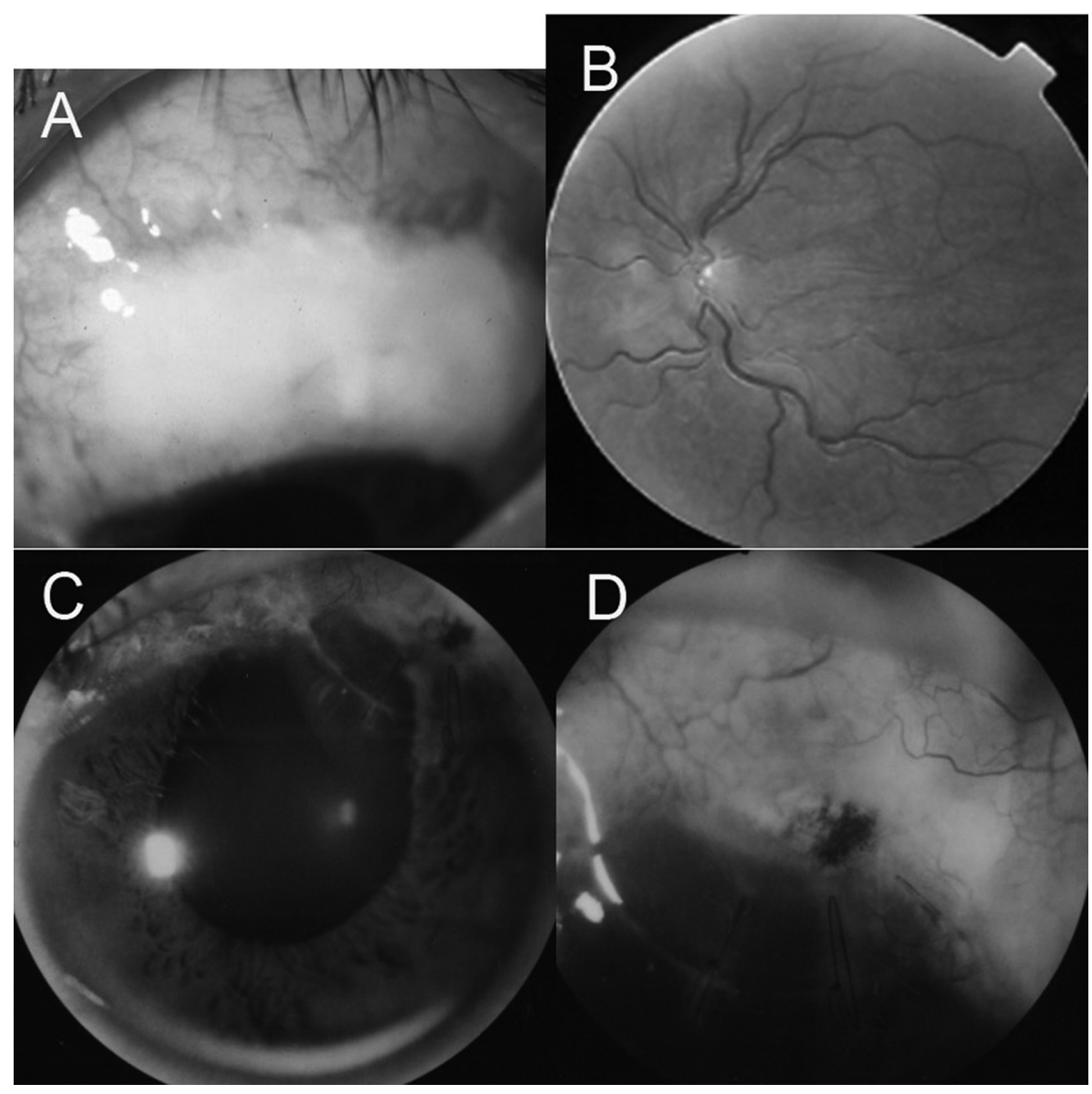

Figure 3 Case 3 had a giant ischemic bleb (A) and hypotony after MMC trabeculectomy. His left fundus showed typical hypotony maculopathy (B). After corneal lamellar grafting, the anterior chamber had remained deep (C) and the IOP had increased because of complete closure of the scleral cleft (D).

Abbreviations: IOP, intraocular pressure; MMC, mitomycin $\mathrm{C}$.

\section{Discussion}

Cases 1 and 2 had complicated bleb leaks from a microhole. Case 1 had combined hypotony with the shallow anterior chamber and circumferential ciliochoroidal detachment while bleb-related infections recurred in case 2 . The occurrence of bleb leaks had been increasing because of the use of antifibrolytic agents, 5-fluorouracil, or MMC, and to time progress after filtering surgeries..$^{20}$ Bleb-related infections, blebitis, or endophthalmitis, are reported to be the most severe complications after MMC trabeculectomy and are closely related to bleb leaks. ${ }^{21,22}$ Microholes can supply a route for bacteria from the ocular surface into the bleb and eye. Case 3 was a rare case of slow-onset hypotony maculopathy with a large ischemic bleb. Generally, hypotony maculopathy after MMC trabeculectomy results from persistent overfiltration, ciliochoroidal detachment, hyposecretion of aqueous humor or leakage from an epithelial defect, a microhole, or insufficient sutures from the early postoperative periods. ${ }^{8-10}$ The IOPs were over $10 \mathrm{mmHg}$ in the early postoperative phase, but both the IOPs and visual acuity decreased slowly over 18 months in case 3 . An experiment has shown that the antifibrotic effects of MMC can continue for the long term..$^{25}$

The treatments for hypotony with overfiltration or bleb leak are summarized in Table $1^{24,26}$ which was modified slightly from Azuara-Blanco. ${ }^{26}$ These therapies give a range of choices, ranging from conservative to surgical treatments. For initial conservative methods, a pressure eye patch and an oral carbonic anhydrase inhibitor are often recommended. Bleb injection of autologous blood, ${ }^{27}$ bandage contact lenses, and topical application of a chemical irritant, ${ }^{28}$ may be the next corrective steps. symblepharon rings or Simmons shell, laser therapy with argon or Nd:YAG laser, ${ }^{29}$ cryotherapy, and diathermy have also been reported as treatment methods before surgical procedures. We tried a pressure eye patch, oral carbonic anhydrase administration and bleb injection of autologous blood in all cases, but with minimal effects. As a next step, we should consider relatively conservative surgical methods, such as compression sutures 
Table I Treatments for hypotony with hyperfilteration or a leaking bleb after MMC trabeculectomy

I. Conservative methods

I) Pressure eye patching

2) Oral carbonic anhydrase inhibitor

3) Topical autologous serum

2. Bandage contact lens, Simmons shell, symblepharon rings

3. Injection of autologous blood

4. Cyanoacrylate glue, fibrin tissue glue

5. Chemical irritants (trichloroacetic acid, sodium nitrate)

5. Cryopexy, diathermy

6. Argon laser, thermal Nd:YAG laser

7. Surgical revision

I) Needling revision, bleb reformation, compression sutures

2) Direct sutures of the scleral flap

3) Removal of the ischemic bleb and patch grafting

(I) Autologous conjunctiva

(2) Autologous or preserved sclera

(3) Preserved cornea

(4) Amniotic membrane

Abbreviation: MMC, mitomycin C.

over the bleb, direct resuture, or scleroconjunctival suture of the scleral flap. In particular, the bleb leak from a microhole generally requires surgical treatment ${ }^{30,31}$ as in cases 1 and 2. Microholes are made repeatedly because of the very thin and weak ischemic bleb wall. Compression sutures had no notable effects in cases 1 and 3 . We tried direct sutures of the sclera flaps but the MMC-treated sclera was too weak to suture in cases 2 and 3. Therefore, we considered performing patch grafting. The materials for patch grafting include the autologous conjunctiva ${ }^{32}$ or amniotic membranes. ${ }^{33}$ The autologous conjunctiva is the most common and easiest to handle of the materials for patch grafting. It is recommended for primary surgery but not for more resistant and more complicated cases. Although almost two-third of cases with conjunctival grafting have maintained a low IOP, the effect is imperfect and bleb leakage often recurs. ${ }^{32}$ More recently, amnionic membranes have been used as patch grafts to reduce stromal melting and promote re-epithelialization in extensive infectious scleral and corneoscleral ulcers. ${ }^{34}$ Amniotic membranes are not yet commercially available and several procedures are necessary to use this membrane clinically in Japan. The other common materials for anterior segment reconstruction are preserved sclera, ${ }^{35,36}$ pericardium, ${ }^{37}$ and dura matter. ${ }^{38}$ Scleral tissue is not readily available in Japan and caution must be taken to avoid immunogenicity. For the cases presented here, a preserved cornea is the most suitable grafting tissue $\mathrm{e}^{39-41}$ because we had to close the scleral cleft completely and enable their IOPs to increase for recovery from long-term treatments. Similar to our report, $\mathrm{Ti}$ and $\operatorname{Tan}^{41}$ reported 20 cases with severe scleral melting after pterygium surgery that were treated with lamellar corneal grafting, and noted that corneal tissue has some constructive advantages over scleral tissue and allows lamellar dissection for a better graft-host fit. For these types of cases, Kosmin and Wishart ${ }^{36}$ treated with full thickness scleral grafting and Mistlberger et $\mathrm{al}^{40}$ with dissection by an Excima laser and lamellar corneal grafting. Mistberger noted that a corneal graft is better than the scleral graft because there is less vascularization and scar formation after corneal grafting than after scleral grafting. Our method slightly differed from those reported previously because the corneal graft completely covered the filtering site when placed over the cornea and sclera.

Although a corneal or sclera patch must be used to close the scleral cleft and to free these cases from long-term complications, the biggest issue was the loss of the IOP-lowering effect of trabeculectomy. Fortunately, IOPs in all cases were maintained with topical medications, despite a temporary rise just after the surgery. When elevated postoperative IOPs cannot be controlled with medications, repeated MMC trabeculectomy may be difficult because of conjunctival conditions and other problems. A Seton shunt operation in the other operative area or cyclophotocoagulation can be considered in this condition.

Corneal lamellar grafting is a reliable and final surgical method to improve severe cases of hypotony maculopathy or bleb leak after MMC trabeculectomy.

\section{Disclosures}

The authors report no conflicts of interest in this work.

\section{References}

1. Chen CW. Enhanced intraocular pressure controlling effectiveness of trabeculectomy by local application of mitomycin-C. Trans Asia Pacific Acad Ophthalmol. 1983;9(1):172-177.

2. Kitazawa Y, Taniguchi T, Nakano Y, Shirato S, Yamamoto T. 5-Fluorouracil for trabeculectomy in glaucoma. Grafes Arch Clin Exp Ophthalmol. 1987;225(6):403-405.

3. Singh K. Mehta K, Shaikh NM, et al. Trabeculectomy with intraoperative mitomycin $\mathrm{C}$ versus 5 -fluorouracil. Postoperative randomized clinical trial. Ophthalmology. 2000;107(12):2305-2309.

4. Palmer SS. Mitomycin C as adjunct chemotherapy with trabeculectomy. Ophthalmology. 1991;98(3):317-321.

5. Beckers HJ, Kinders KC, Webers CA. Five-year results of trabeculectomy with mitomycin C. Grafes Arch Clin Exp Ophthalmol. 2003;241(2):106-110.

6. Fontana H, Nouri-Mahdavi K, Lumba J, Ralli M, Caprioli J. Trabeculectomy with mitomycin C: Outcomes and risk factors for failure in phakic open-angle glaucoma. Ophthalmology. 2006;113(6):930-936.

7. Shigeeda T, Tomidokoro A, Chen YN, Shirato S, Araie M. Long-term follow-up of initial trabeculectomy with mitomycin $\mathrm{C}$ for primary open-angle glaucoma in Japanese patients. J Glaucoma. 2006;15(3): 195-199. 
8. Shields MB, Scroggs MW, Sloop CM, Simmons RB. Clinical and histopathologic observations concerning hypotony after trabeculectomy with adjunctive mitomycin C. Am J Ophthalmol. 1993;116(6):673-683.

9. Suemori-Matsushita H, Okabe I, Yamamoto T, et al. Hypotonic maculopathy following trabeculectomy with mitomycin C. Nippon Ganka Gakkai Zasshi. 1995;99(3):312-317. Japanese.

10. Liebmann JM, Ritch R. Complications of glaucoma filtering surgery. In: Ritch R, Shields MB, Krupin T, editors. The Glaucomas. 2nd ed. St. Louis, MO: CV Mosby; 1996. p. 1703-1706.

11. Geijssen HC, Greve EL. Prevention of hypotony after trabeculectomies with mitomycin. Doc Ophthalmol. 1993;85(1):45-49.

12. Morinelli EN, Sidoti PA, Heuer DK, et al. Laser suture lysis after mitomycin C trabeculectomy. Ophthalmology. 1996;103(2):306-314.

13. Kapetansky FM. Laser suture lysis after trabeculectomy. J Glaucoma. 2003;12(4):316-320.

14. Demailly P, Lavat P, Kretz G, Jeanteur-Lunel MN. Non-penetrating deep sclerectomy (NPDS) with or without collagen device (CD) in primary open-angle glaucoma: Middle-term retrospective study. Int Ophthalmol. 1997;20(1-3):131-140.

15. Fukuchi T, Suda K, Nakatsue T, Hara H, Abe H. Midterm results and the problems of nonpenetrating lamellar trabeculectomy with mitomycin C for Japanese glaucoma patients. Jpn J Ophthalmol. 2007;51(1):34-40.

16. Anand N, Arara S, Clowers M. Mitomycin C augmented glaucoma surgery: Evolution of filtering bleb avascularity, transconjunctival oozing, and leaks. Br J Ophthalmol. 2006;92(2):175-180.

17. Belyea DA, Dan JA, Stamper RL, Lieberman MF, Spencer WH. Late onset of sequential multifocal bleb leaks after glaucoma filtration surgery with 5-fluorouracil and mitomycin C. Am J Ophthalmol. 1997;124(1):40-45.

18. Greenfield DS, Liebmann JM, Jee J, Ritch R. Late-onset bleb leaks after glaucoma filtering surgery. Arch Ophthalmol. 1998;116(4):443-447.

19. Hu CY, Matsuo H, Tomita G, et al. Clinical characteristics and leakage of functioning blebs after trabeculectomy with mitomycin-C in primary glaucoma patients. Ophthalmology. 2003;110(2):345-352.

20. Matsuo H, Tomidokoro A, Suzuki Y, Shirato S, Araie M. Late-onset transconjunctival oozing and point leak of aqueous humor from filtering bleb after trabeculectomy. Am J Ophthalmol. 2002;133(4):456-462.

21. Mochizuki K, Jikihara S, Ando Y, Hori N, Yamamoto T, Kitazawa Y. Incidence of delayed onset infection after trabeculectomy with adjunctive mitomycin C or 5-fluorouracil treatment. Br J Ophthalmol. 1997;81(10):877-883.

22. Muckley ED, Lehrer RA. Late-onset blebitis/endophthalmitis: Incidence and outcomes with mitomycin C. Optom Vis Sci. 2004;81(7):499-504.

23. Fukuchi T, Hayakawa Y, Hara H, Abe H. Cornal endothelial damage after trabeculectomy with Mitomycin C in two patients with glaucoma with cornea guttata. Cornea. 2002;21(3):300-304.

24. Spaeth GL. Glaucoma surgery. In: Spaeth GL, editor. Ophthalmic Surgery: Principles and Practice. Philadelphia, MA: WB Saunders; 1982. p. 335-343.
25. Nuyts RM, Felten PC, Pels E, et al. Histopathologic effects of mitomycin $\mathrm{C}$ after trabeculectomy in human glaucomatous eyes with persistent hypotony. Am J Ophthalmol. 1994;118(2):225-237.

26. Azuara-Blanco A, Katz LJ. Dysfunctional filtering blebs. Surv Ophthalmol. 1998;43(2):93-126.

27. Smith MF, Magauran R, Doyle JW. Treatment of postfiltration bleb leak by bleb injection of autologous blood. Ophthalmic Surg. 1994;25(9):636-637.

28. Zalta AH, Wieder RH. Closure of leaking blebs with cyanoacrylate tissue adhesive. Br J Ophthalmol. 1991;75(3):170-173.

29. Geyer O. Management of large, leaking, and inadvertent filtering blebs with the neodymium: YAG laser. Ophthalmology. 1998;105(6):983-987.

30. Budenz DL, Chen PP, Weaver YK. Conjunctival advancement for late-onset filtering bleb leaks: Indications and outcomes. Arch Ophthalmol. 1999;117(8):1014-1019.

31. Loane ME, Galanopoulos A. The surgical management of leaking filtering blebs. Curr Opin Ophthalmol. 1999;10(2):121-125.

32. Wilson MR, Kotas-Neumann R. Free conjunctival patch for repair of persistent late bleb leak. Am J Ophthalmol. 1994;117(5):569-574.

33. Soong HK, Meyer RF, Wolter JR. Fistula excision and peripheral grafts in the treatment of persistent limbal wound leaks. Ophthalmology. 1988;95(1):31-36.

34. Ma DH, Wang SF, Su WY, Tsai RJ. Amniotic membrane graft for the management of scleral melting and corneal perforation in recalcitrant infectious scleral and corneoscleral ulcers. Cornea. 2002;21(3): 275-283.

35. Melamed S, Ashkenazi I, Belcher DC, Blumenthal M. Donor scleral graft patching for persistent filtration bleb leak. Ophthalmic Surg. 1991;22(3):164-165.

36. Kosmin AS, Wishart PK. A full-thickness scleral graft for the surgical management of a late filtration bleb leak. Ophthalmic Surg Lasers. 1997;28(6):461-468.

37. Schein OD. The use of processed pericardial tissue in anterior ocular segment reconstruction. Am J Ophthalmol. 1998;125(4):549-552.

38. Brandt JD. Patch grafts of dehydrated cadaveric dura mater for tube-shunt glaucoma surgery. Arch Ophthalmol. 1993;111(10): 1436-1439.

39. Soong HK, Meyer RF, Wolter JR. Fistula excision and peripheral grafts in the treatment of persistent limbal wound leaks. Ophthalmology. 1988;95(1):31-36.

40. Mistlberger A, Biowski R, Grabner G. Repair of a late-onset filtering bleb leak using a corneal graft shaped with an Excimer laser. Ophthalmic Surg Lasers. 2001;32(5):428-431.

41. Ti S, Tan DTH. Tectonic corneal lamellar grafting for severe scleral melting after pterygium surgery. Ophthalmology. 2003;110(6): $1126-1136$.
Clinical Ophthalmology

\section{Publish your work in this journal}

Clinical Ophthalmology is an international, peer-reviewed journal covering all subspecialties within ophthalmology. Key topics include: Optometry; Visual science; Pharmacology and drug therapy in eye diseases; Basic Sciences; Primary and Secondary eye care; Patient Safety and Quality of Care Improvements. This journal is indexed on Submit your manuscript here: http://www.dovepress.com/clinical-ophthalmology-journal

\section{Dovepress}

PubMed Central and CAS, and is the official journal of The Society of Clinical Ophthalmology (SCO). The manuscript management system is completely online and includes a very quick and fair peer-review system, which is all easy to use. Visit http://www.dovepress.com/ testimonials.php to read real quotes from published authors. 